\title{
EL RECONOCIMIENTO PARCIAL DE LA RESPONSABILIDAD DEL ESTADO COLOMBIANO EN EL SISTEMA INTERAMERICANO DE DERECHOS HUMANOS. CASOS MAPIRIPÁN, ITUANGO Y LA ROCHELA*
}

\author{
Xiomara Lorena ROMERO PÉREZ**
}

RESUMEN: Este artículo busca ahondar en el estudio de la figura del reconocimiento parcial de responsabilidad por parte de los Estados en el Sistema Interamericano de Protección de los Derechos Humanos tomando como parámetro de análisis algunos casos colombianos en los que esta aceptación se muestra como una nueva estrategia de defensa de este Estado, situación frente a la cual la Corte Interamericana, dada la ausencia de regulación para estos eventos, ha tenido que desarrollar el tema a través de su jurisprudencia.

ABSTRACT: This article seeks to go deeply into the study of the figure of the partial recognition of responsibility on the part of the States into the Inter-American System of Protection of the Human rights taking as a parameter of analysis some Colombian cases in which this acceptance appears as a new strategy of defense of this State, situation opposite to which the Inter-American Court, given the absence of regulation for these events, has had to develop the topic through its jurisprudence.

RÉSUMÉ: Cet article cherche pénétrer dans l'étude de la figure de la reconnaissance partielle de la responsabilité des États dans le Système Interaméricain de Protection des Droits de l'homme en prenant comme paramètre d'analyse quelques cas colombiens dans lesquels cette acceptation se montre comme une nouvelle stratégie de défense de cet État, de la situation en face de laquelle la Cour Interaméricaine, donnée l'absence de régulation pour ces évènements, a eu à développer le sujet à travers de sa jurisprudence.

* Artículo recibido el 16 de junio de 2008 y aceptado para su publicación el 8 de agosto de 2008.

** Profesora e investigadora en el Departamento de Derecho Constitucional de la Universidad Externado de Colombia. 
SUMARIO: I. Introducción. II. Aspectos comunes en el reconocimiento parcial de responsabilidad por parte del Estado colombiano en los casos Mapiripán, Ituango y La Rochela. III. Efectos jurídicos que la Corte Interamericana otorga al reconocimiento parcial de responsabilidad del Estado colom-

biano. IV. Conclusiones.

\section{INTRODUCCIÓN}

Los casos que serán objeto de análisis corresponden a los pronunciamientos más recientes de la Corte Interamericana de Derechos Humanos (en adelante Corte o ente jurisdiccional) en relación con el Estado colombiano (en adelante Estado o ente estatal), que reconoció la competencia contenciosa de la misma el día 21 de junio de 1985. Estas tres situaciones, nos referimos a los casos de Mapiripán, ${ }^{1}$ Ituango ${ }^{2}$ y la Rochela, ${ }^{3}$ han sido calificadas por la Corte como masacres ${ }^{4}$ y tienen como nota característica, según las pruebas recaudadas por este ente jurisdiccional, el hecho de que el Estado, bien sea por acción o por omisión, favoreció el actuar de grupos de autodefensa o paramilitares en desmedro de la protección de los derechos humanos de la población civil.

Al respecto, es importante llamar la atención de que sólo en uno de los casos que serán objeto de estudio, la masacre de la Rochela, los sucesos se desarrollaron meses antes de que salieran del ordenamiento jurídico colombiano los decretos que favorecían el funcionamiento de grupos de autodefensas, nos referimos al Decreto 815 de 1989. No obstante, ni siquiera frente a los otros dos casos, Mapiripán e Ituango, el argumento de que estas normas habían sido derogadas fue suficiente para que el

1 Caso de la Masacre de Mapiripán vs. Colombia, sentencia del 15 de septiembre de 2005, Fondo, reparaciones y costas, de la Corte Interamericana de Derechos Humanos, en http://www.corteidh.or.cr.

2 Caso de las Masacres de Ituango vs. Colombia, sentencia del 1o. de julio de 2006, Excepción preliminar, fondo, reparaciones y costas, de la Corte Interamericana de Derechos Humanos, en http://www.corteidh.or.cr.

3 Caso de la masacre de la Rochela vs. Colombia, sentencia del 11 de mayo de 2007, Fondo, reparaciones y costas, de la Corte Interamericana de Derechos Humanos, en http://www.corteidh.or.cr.

4 Acorde con la 22a. ed. del Diccionario de la Real Academia Española masacre significa: "Matanza de personas, por lo general indefensas, producida por ataque armado o causa parecida", en http://www.corteidh.or.cr. 
Estado colombiano librara su responsabilidad puesto que, con base en el material probatorio, se hizo notorio que estos grupos actuaron con el conocimiento y bajo el consentimiento de las autoridades estatales poniendo en peligro a la sociedad civil y comprometiendo de lleno la responsabilidad estatal.

Concretamente el caso de Mapiripán versa sobre los hechos ocurridos entre el 15 y 20 de julio de 1997 en esa población del Estado colombiano, lugar donde un grupo paramilitar torturó y asesinó a por lo menos 49 personas civiles en el municipio ubicado en el departamento de Meta.

En esta oportunidad la Corte llegó al convencimiento de que miembros de la fuerza pública del Estado ayudaron de forma activa a grupos paramilitares para que incursionaran en esta población civil y efectuaran homicidios a discreción; ayudas que se concretaron en la facilitación de transporte aéreo y terrestre para miembros de ese grupo, a lo que debe añadirse el hecho de que de forma posterior no se brindó la ayuda oportuna a la población.

Por su parte los hechos que enmarcaron el caso de las masacres de Ituango datan de los meses de junio de 1996 y octubre de 1997 en los municipios de El Aro y La Granja respectivamente, en ellos se refleja que grupos paramilitares se desplazaron por vía terrestre a estos corregimientos del municipio de Ituango, departamento de Antioquia en Colombia, para realizar ejecuciones selectivas con la aquiescencia o al menos a la vista de la fuerza pública sin que los uniformados tomaran acciones en relación con esa movilización.

En lo que atañe a la masacre de la Rochela, los sucesos que rodearon este caso se refieren a que el día 18 de enero de 1989 un grupo paramilitar ejecutó a funcionarios de la fiscalía ${ }^{5}$ mientras que éstos desarrollaban su trabajo en el corregimiento de La Rochela, en el Bajo Simacota, departamento de Santander en Colombia, ante la pasividad de las autoridades estatales que no les brindaron la seguridad adecuada.

En relación con este sucinto recuento de los hechos que enmarcaron estos tres casos fallados por la Corte surge un interrogante a priori y es plantearse ¿qué puede hacer un Estado frente a una acusación en el sistema interamericano?

5 Institución estatal colombiana encargada de la investigación en las causas penales. 
Como lo analiza el doctor Carmona Tinoco ${ }^{6}$ los Estados pueden tomar diversas posturas, a saber: i) una primera posibilidad es cuestionar la competencia de la Corte, es decir, oponerse a ultranza a que ésta conozca del caso llegando incluso a separarse de la Convención Americana; ${ }^{7}$ ii) otra opción es cuestionar el procedimiento surtido ante la Comisión Interamericana (en adelante Comisión), es decir, alegar la vulneración al debido proceso durante este trámite; iii) una alternativa más es que el Estado decida participar activamente en el proceso, o iv) que el Estado decida simplemente aceptar su responsabilidad.

Posturas que, aunándonos al autor en cita, conservan una correspondencia con las etapas que ha tenido que soslayar la Corte durante su funcionamiento en relación con la actitud de los Estados.

Lo curioso de los casos seleccionados es precisamente que no se enmarcan simple y llanamente en las hipótesis expuestas con antelación, sino que son ejemplos de una posición híbrida en la cual un Estado, a pesar de haber aceptado su responsabilidad, se reserva la prerrogativa de seguir debatiendo ante la Corte parte de los hechos y/o pretensiones presentados por la Comisión o por los representantes de las víctimas, punto en el cual es necesario advertir que la Corte ha aceptado que las víctimas presenten un escrito de argumentos y solicitudes del cual pueden desprenderse la violación de derechos que no fueron alegados por parte de la Comisión, según se analizará al interior del texto. ${ }^{8}$

Es así como nos encontramos ante un reconocimiento parcial de responsabilidad de un Estado, lo que nos lleva a proponer un segundo interrogante y es saber ¿qué diferencia existe entre aceptar una responsabilidad total y aceptar una responsabilidad parcial en un caso sometido a decisión ante la Corte?

$\mathrm{Al}$ respecto es necesario recordar algunos artículos del Reglamento de la Corte que resultan del todo pertinentes así, por ejemplo, en el artículo 53.2 se establece que una vez el Estado demandado comunique a

6 Carmona Tinoco, Jorge Ulises, "Participación de los Estados en el proceso ante la Corte", en Becerra Ramírez, Manuel (coord.), La Corte Interamericana de Derechos Humanos a veinticinco años de su funcionamiento, México, UNAM, Instituto de Investigaciones Jurídicas, 2007, pp. 7 y ss.

7 El caso más citado es el de Trinidad y Tobago.

8 Véase infra, p. 229. 
la Corte el allanamiento a las pretensiones, ésta resolverá sobre su procedencia y efectos jurídicos. ${ }^{9}$

En armonía con lo anterior, el artículo 55 otorga una amplia facultad a la Corte al disponer que este ente jurisdiccional puede decidir si se prosigue o no con el examen del caso. ${ }^{10}$

Del contenido de estos artículos se desprende, entre otras cosas, lo siguiente: i) que el Reglamento de la Corte sólo contempla el allanamiento total por parte de los Estados más no considera el allanamiento parcial; ii) que el Reglamento sólo hace mención al allanamiento de pretensiones más no al eventual allanamiento de los hechos; iii) que en dicho Reglamento se resalta la potestad de la Corte para decidir sobre la procedencia del allanamiento, así como, iv) la potestad de la Corte para continuar o no con el examen del caso cuando esta situación se presente.

Si quisiéramos hilar más delgado diríamos incluso que el Reglamento de la Corte sólo se refiere al término de allanamiento mas no al reconocimiento de responsabilidad; no obstante, la Corte al abordar el tema ha entendido que la expresión utilizada por los Estados en este sentido se enmarca dentro de lo que en su Reglamento se regula como allanamiento, incluso en algunos casos se ha analizado de forma separada los efectos que a cada concepto corresponden, como se resalta en el voto concurrente del juez Sergio García Ramírez en el caso de la masacre de Mapiripán sin que por este hecho hayan dejado de emplearse como sinónimos por parte del ente jurisdiccional.

De estos breves planteamientos podría deducirse que cuando se presenta un reconocimiento parcial por parte de un Estado y, más aún, cuando el mismo versa sobre los hechos del litigio y no sobre las pretensiones, la Corte debería rechazar o, al menos, negar la viabilidad de esta manifestación con fundamento en que en estricto sentido, como lo resal-

9 El texto del artículo 53.2 del Reglamento de la Corte es: "Si el demandado comunicare a la Corte su allanamiento a las pretensiones de la parte demandante y a las de los representantes de las presuntas víctimas, sus familiares o representantes, la Corte, oído el parecer de las partes en el caso, resolverá sobre la procedencia del allanamiento y sus efectos jurídicos. En este supuesto, la Corte procederá a determinar, cuando fuere el caso, las reparaciones y costas correspondientes", en http://www.corteidh.or.cr/reglamento.cfm.

10 El artículo 55 del Reglamento de la Corte establece: "La Corte, teniendo en cuenta las responsabilidades que le incumben de proteger los derechos humanos, podrá decidir que prosiga el examen del caso, aun en presencia de los supuestos señalados en los artículos precedentes", en http://www.corteidh.or.cr/reglamento.cfm. 
tamos de forma precedente, la Corte no goza de la competencia para pronunciarse sobre el mismo, acorde con el tenor literal del Reglamento que la rige.

Sin embargo, la Corte ha sido proclive para dar efectos al reconocimiento parcial de responsabilidad de los Estados, es más, ha aceptado el allanamiento sobre los hechos, lo que ha compensado no sólo al ser muy estricta al momento de determinar si continúa o no con el estudio de fondo del caso, sino con la precisión con la que evalúa y establece los hechos y las pretensiones sobre los cuales seguirá su examen. En síntesis podríamos afirmar que, en principio, la diferencia esencial entre los dos reconocimientos estriba en que en el reconocimiento parcial el estudio de fondo del caso necesariamente continuará por cuanto habrá hechos o pretensiones pendientes de comprobación.

Se resalta la expresión en principio porque aun cuando hubiese un reconocimiento total de responsabilidad por parte de un Estado, la Corte conserva la potestad de efectuar un estudio de fondo, lo que significa que ésta no necesariamente debe limitarse a establecer las reparaciones a que haya lugar de acuerdo con el artículo 55 del Reglamento de la Corte.

Así, por ejemplo, en el caso Montero Aranguren y otros (Retén de Catia) vs. Venezuela, donde el Estado admitió su responsabilidad sin reservas, la Corte decidió desestimar el reconocimiento sobre una de las pretensiones al no considerarlo como un derecho autónomo y, por tanto, continuó con el estudio de fondo en relación con esa solicitud. ${ }^{11}$

Continuando con nuestras interpelaciones ¿qué podría justificar este actuar de la Corte que algunos verían como contrario a la estricta literalidad de su Reglamento? Quizá, como lo explica el doctor Sergio García Ramírez en su voto razonado en el caso de las masacres de Ituango, es necesario recordar que los casos objeto de análisis y juzgamiento por parte de la Corte versan sobre la aplicación e interpretación de instrumentos internacionales de derechos humanos, por lo que se trata de un enjuiciamiento sobre la violación a los mismos y allí no hay fórmulas matemáticas o precisas por lo que hay que alentar la tímida actuación que los Estados han adoptado recientemente en algunos casos al reconocer, así sea parcialmente, su responsabilidad mostrando cierta ética en su

11 Caso Montero Aranguren y otros (Retén de Catia) vs. Venezuela, sentencia del 5 de julio de 2006, Fondo, reparaciones y costas, de la Corte Interamericana de Derechos Humanos en http://www.corteidh.or.cr. 
obrar. ${ }^{12}$ En todo caso para aquellos más apegados a la literalidad de las normas, recordemos que el artículo 53.2 del Reglamento de la Corte expresamente le concede a ésta la potestad para dar los efectos jurídicos que estime convenientes al allanamiento que se le presenta, efectos que podrían ser parciales en la medida en que no figura ninguna restricción al respecto.

Hechas estas anotaciones, impera señalar que el objeto de éste escrito es ahondar en la figura del reconocimiento parcial de responsabilidad por parte de un Estado para lo cual, como señalábamos en el inicio, hemos seleccionado tres casos en los que el Estado colombiano ha sido parte y ha efectuado una manifestación de esa naturaleza. Por lo que nos concentraremos en estudiar, tanto desde una óptica procesal como sustancial, los términos en que el Estado efectuó dicha declaración para, de forma posterior, abordar las consecuencias y el alcance que la Corte otorgó a estas proposiciones.

A su vez, el artículo busca mostrar los aspectos comunes de los tres casos objeto de análisis, resaltando, durante estas reflexiones, los puntos positivos y aquellos que podríamos calificar como negativos en el ejercicio de esta nueva estrategia de defensa por parte del Estado colombiano. De la misma forma resaltaremos los contenidos de vanguardia de las decisiones emitidas por la Corte sobre temas que ha tenido que sortear y que quizá no fueron inicialmente previstos en el Reglamento que la gobierna, por lo que en este artículo también se formulan propuestas para sacar un mayor provecho de esta nueva actitud de los Estados.

\section{ASPECTOS COMUNES EN EL RECONOCIMIENTO PARCIAL DE RESPONSABILIDAD POR PARTE DEL ESTADO COLOMBIANO EN LOS CASOS MAPIRIPÁN, ITUANGO Y LA ROCHELA}

Como lo destacábamos en la introducción, en los tres casos en cuestión el Estado colombiano efectuó un reconocimiento parcial de su responsabilidad, lo que significa que el Estado aceptó de forma expresa la vulneración de algunos preceptos de la Convención Americana de Derechos Humanos. Así las cosas, en este apartado analizaremos los términos

12 En igual sentido: Caso Ximenes Lopes vs. Brasil, Fondo, reparaciones y costas, sentencia del 4 de julio de 2006, pp. 22 y ss, de la Corte Interamericana de Derechos Humanos en http://www.corteidh.or.cr. 
en que el Estado efectuó dicho reconocimiento centrándonos en aquellos items que resultan comunes a los tres casos objeto de estudio.

Desde esa perspectiva nos limitaremos a tratar tres temas que, en nuestro criterio, sintetizan la postura del Estado y a la vez están presentes en todos los casos elegidos: 1) la etapa procesal en que se realizó el reconocimiento, esto es, el momento de la litis en que el Estado manifestó de forma expresa que aceptaba su responsabilidad; 2) el contenido de la manifestación del Estado, es decir, las expresiones que se emplearon en los reconocimientos de responsabilidad y los límites que enmarcaron los mismos, y 3) la insistencia en formular excepciones previas pues, como lo expondremos más adelante, un aspecto común en la defensa del Estado es que, aun cuando ha efectuado un reconocimiento parcial de responsabilidad, continúa con la alegación de excepciones en su favor.

\section{Etapa procesal en la que el Estado reconoce parcialmente su responsabilidad}

Parecería que detenerse en el análisis del momento en que el Estado efectuó este reconocimiento carecería de utilidad por cuanto, en definitiva, lo cierto es que independientemente de la etapa procesal el ente estatal realizó una aceptación cuyos efectos corresponde determinar a la Corte. ${ }^{13}$

No obstante lo anterior, resulta llamativo observar que el mencionado reconocimiento se llevó a cabo, en dos de los tres casos sujetos a análisis, de forma conjunta con la presentación del escrito de formulación excepciones, contestación de la demanda y pronunciamiento sobre los argumentos y solicitudes radicadas por parte de los representantes de las víctimas; lo cual nos hace pensar en que no es del todo indiferente para el Estado el momento procesal en que se realizaron estas manifestaciones.

Puntualmente en el caso de Mapiripán el reconocimiento parcial se efectuó un año después de la presentación del escrito de formulación de excepciones, contestación de la demanda y pronunciamiento sobre los argumentos y solicitudes de los representantes de las víctimas; así, encontramos que para la época en que el Estado realizó dicho reconocimiento,

13 Cfr. artículo 53.2 del Reglamento de la Corte Interamericana de Derechos Humanos, cit., nota 9. 
la Corte ya había ordenado la práctica de diversos testimonios y peritajes fundada, por obvias razones, en la manifestación inicial del ente estatal en la que éste enfatizaba el rechazo a cualquier señalamiento en su contra. ${ }^{14}$

Por su parte en el caso de las masacres de Ituango, al igual que en el caso de la masacre de La Rochela, el reconocimiento parcial de responsabilidad se realizó de forma conjunta en el escrito de formulación de excepciones, contestación de la demanda y pronunciamiento sobre las solicitudes y argumentos de las víctimas.

Allí el Estado aceptó la violación de algunos derechos plasmados en la Convención Americana de Derechos Humanos en relación con las víctimas identificadas en la demanda, planteamiento que en definitiva también resultó ser parcial pues en el escrito de solicitudes y argumentos presentado por parte de los representantes de las víctimas se señalaron más perjudicados. En relación con otros temas esta aceptación fue más allá, pues se planteó la posibilidad de presentar una propuesta de reparación concertada con aquellos que acreditaran su calidad de víctimas.

Concretamente el Estado reconoció su responsabilidad internacional por la violación de los artículos 4.1 (derecho a la vida), 5.1 (derecho a la integridad personal), 7.1 (derecho a la libertad personal) y 21.1 (derecho a la propiedad privada) de la Convención, en perjuicio de aquellas personas señaladas en la demanda presentada por la Comisión. Adicionalmente en esta ocasión el Estado identificó de forma tajante qué violaciones consideraba que no le eran atribuibles y a su vez guardó silencio respecto a otros señalamientos. ${ }^{15}$

14 En esta oportunidad el Estado indicó: "con fundamento en las decisiones proferidas por las autoridades jurisdiccionales y disciplinarias internas y por los hechos ocurridos en el municipio de Mapiripán entre el 15 y el 20 de julio de 1997 [el Estado] manifiesta pública y expresamente lo siguiente:... 2. Reconoce su responsabilidad internacional por la violación de los artículos 4(1), 5(1) y [5](2), y 7 (1) y [7](2) de la Convención Americana sobre Derechos Humanos, en relación con los hechos ocurridos en Mapiripán entre el 15 y el 20 de julio de 1997'. Corte Interamericana de Derechos Humanos, op. cit, nota 1 .

15 Sobre el punto la Corte estableció que: “[E]1 Estado afirmó no haber violado los artículos 19 (Derechos del Niño), 8.1 (Garantías Judiciales) y 25.1 (Protección Judicial) de la Convención, alegados tanto por la Comisión como por los representantes (supra párrs. 3 y 18), ni los artículos 6 (Prohibición de la Esclavitud y Servidumbre) y 22 (Derecho de Circulación y de Residencia) de la Convención, alegados por los representantes... $[\mathrm{P}]$ or otra parte, el Estado no se refirió a la presunta violación del artículo 5o. (Derecho a 
Por último, en lo que concierne a la masacre de La Rochela debemos recordar que de forma previa ante la Comisión el vicepresidente de Colombia había expresado en nombre del Estado colombiano un reconocimiento de la vulneración a ciertos derechos humanos. ${ }^{16} \mathrm{~A}$ su vez, ante la Corte el Estado aceptó la vulneración de algunos derechos contemplados en la Convención Americana, escrito en el que se mencionó de forma detallada cada uno de los preceptos de la citada Convención donde estos derechos estaban consagrados. ${ }^{17}$

De lo señalado hasta aquí se pueden abstraer las diversas posturas que ha asumido el Estado colombiano en torno a la posibilidad de efectuar un reconocimiento de responsabilidad en el Sistema Interamericano de Derechos Humanos: la primera, que vislumbra una actitud tendiente a permitir que avance el proceso internacional sin que se efectúe ninguna

la Integridad Personal) de la Convención, en perjuicio de las personas ejecutadas y sus familiares, de conformidad con lo alegado por los representantes en su escrito de solicitudes y argumentos. Asimismo, Colombia no se refirió a la presunta violación de los artículos 5o. (Derecho a la Integridad Personal), 7o. (Derecho a la Libertad Personal) y 21 (Derecho a la Propiedad Privada) de la Convención, en perjuicio de las personas señaladas por los representantes en su escrito de solicitudes y argumentos (supra párr. 18) y que no fueron comprendidas dentro del allanamiento del Estado (supra párr. 19)". Corte Interamericana de Derechos Humanos, op. cit, nota 2.

16 Puntualmente el vicepresidente manifestó: “[E]n nombre del Estado colombiano y en mi condición de Vicepresidente de la República reconozco la responsabilidad internacional del Estado por no haber adoptado las medidas necesarias para garantizar la seguridad de nuestros funcionarios; esta omisión permitió la violación de sus derechos a la vida e integridad personal". Cfr. Escrito de contestación de la demanda (expediente sobre fondo y eventuales reparaciones y costas, Tomo III, folio 862); y demanda de la Comisión, Apéndice 3, folio 1809.

17 En los antecedentes de la sentencia de fondo puede leerse que el Estado aceptaba: b. [S]u responsabilidad internacional, por acción y por omisión, por la violación de los derechos consagrados en los artículos 4o. (derecho a la vida), 5o. (derecho a la integridad personal) y 7 o. (derecho a la libertad personal), en relación con la obligación general establecida en el artículo 1.1 de la Convención Americana respecto de las [víctimas fallecidas y las víctimas sobrevivientes]. c. [S]u responsabilidad internacional por la violación del derecho a la integridad personal protegida en el artículo 5o. de la Convención, respecto de los familiares de las víctimas. d. [S] u responsabilidad internacional, de manera parcial, respecto de la violación de los artículos 80. (Garantías judiciales) y 25 (Protección Judicial), en conexión con [el] artículo 1.1 (Obligación de Respetar los Derechos) de la Convención Americana, en perjuicio de las víctimas y sus familiares en el caso La Rochela, pues considera que aún existen procesos judiciales pendientes encausados para sancionar a los responsables intelectuales y materiales. Corte Interamericana de Derechos Humanos, op. cit., nota 3. 
admisión de responsabilidad por más evidente que resulten los hechos; la segunda, en la cual se hace un reconocimiento a instancias de la Corte sin realizar mayores precisiones sobre su alcance, y la tercera, que envuelve un reconocimiento previo ante la Comisión y que, además ante la Corte, se acompaña con un listado taxativo sobre las vulneraciones a los derechos humanos que se aceptan y las que no.

Esta última postura muestra una posición más seria que no niega la evidencia de los hechos, la cual permite que el Sistema Regional de Protección de los Derechos Humanos no malgaste sus recursos con la práctica de pruebas en relación con hechos sobre los cuales de forma previa se ha aceptado la responsabilidad y que, además, posibilita una mejor labor por parte de la Corte en la medida en que precisar los derechos sobre los que se admite una vulneración ofrece una mayor claridad sobre aquellos que continúan en discusión.

Consideraciones a las que bien podrían agregarse la preservación de los principios de economía procesal y colaboración con la justicia, que apuntan a evitar el desgaste de un aparato jurisdiccional, por cuanto existirán hechos o pretensiones que no requerirán de prueba y, por tanto, harán que el proceso se torne más expedito $\mathrm{y}$, en consecuencia, menos oneroso. ${ }^{18}$

Posiblemente sea una coincidencia que estas manifestaciones, con sus respectivos alcances, se hayan producido en este orden cronológico, pero nos gustaría pensar que esta actitud obedece a un avance en las políticas del Estado colombiano para hacer frente a las demandas internacionales de derechos humanos en el Sistema Interamericano.

\section{Contenido del reconocimiento parcial de la responsabilidad}

Hasta aquí hemos abordado un aspecto de tinte procesal en relación con el reconocimiento parcial de responsabilidad efectuado por el Estado colombiano en los tres casos citados, en la medida en que, hemos dado respuesta a la pregunta de cuándo se realizó dicha aceptación. Ahora, en este acápite, nos centraremos en dilucidar ¿qué se reconoce?, esto es, entraremos al fondo del asunto para determinar qué es exactamente lo que

18 Recordemos que el presupuesto con el que labora la Corte Interamericana es limitado por lo cual los gastos deben ser los estrictamente necesarios. Sobre el tema consúltese Fix-Zamudio, Héctor, op. cit., nota 6, pp. XLIII y ss. 
acepta el Estado colombiano; acaso los hechos expuestos por la Comisión y las pretensiones que ésta le opone o los hechos y pretensiones que en algunas oportunidades propusieron de forma autónoma los representantes de las víctimas. En suma, el interrogante que buscamos absolver es si el reconocimiento del Estado versa exclusivamente sobre la postura de la Comisión, o si su aceptación también abarca la posición de los representantes de las víctimas.

De una lectura juiciosa de los tres reconocimientos parciales de responsabilidad, objeto de análisis, se desprende que el Estado siempre alude a la violación de artículos de la Convención Americana, es decir, no se refiere a los hechos de forma detallada, sino a los derechos humanos vulnerados lo que, en principio, correspondería con las pretensiones propuestas tanto por la Comisión como por las víctimas.

Sin embargo, en estos tres casos encontramos una manifestación expresa por parte del Estado mediante la cual se aprecia que su reconocimiento se circunscribió a lo señalado por la Comisión en su demanda, independientemente de que este escrito guardara o no una total correspondencia con el escrito de solicitudes y argumentos de las víctimas, lo que justificaba el ente estatal indicando que sólo reconocía a la Comisión como legítima actora dentro del Sistema Interamericano de Protección de los Derechos Humanos y que, por lo mismo, no efectuaba ninguna manifestación en relación con la postura asumida por las víctimas.

Concretamente en estos tres casos el Estado arguyó que los escritos de solicitudes, pruebas y argumentos de las víctimas se asimilan a una demanda y, por lo mismo, debían ser rechazados por parte de la Corte en la medida en que, según afirmó, sólo la Comisión goza de legitimidad activa en este proceso internacional, postura que sustentó basándose en el artículo 61 de la Convención Americana que establece en su numeral 1o. que "sólo los Estados Partes y la Comisión tienen derecho a someter un caso a la decisión de la Corte"; precepto por el cual el Estado concluyó que los peticionarios no pueden formular nuevas pretensiones, sino limitar su participación a dar sustento a las que previamente habían sido presentadas por la Comisión, pues lo contrario conllevaría a obligar al ente estatal a contestar una segunda demanda.

Ciertamente en el caso de Mapiripán, de forma posterior al reconocimiento parcial de la responsabilidad, el Estado precisó que su aceptación 
sólo versaba sobre la demanda presentada por la Comisión Interamericana de Derechos Humanos. ${ }^{19}$

De la misma forma en el caso de las masacres de Ituango el Estado en su reconocimiento se limitó a pronunciarse sobre las posibles vulneraciones de los derechos que listaba la Comisión, guardando silencio en relación con el escrito de solicitudes y argumentos presentado por los representantes de las víctimas que se refería, entre otros, a otras posibles víctimas, así como a la vulneración de otros derechos que no habían sido mencionados por la Comisión.

Más exactamente, el Estado no hizo ninguna manifestación sobre la posible vulneración a los artículos 5o. (derecho a la integridad personal) 7o. (libertad personal) y 21 (propiedad privada) de la Convención, pretensiones que fueron formuladas exclusivamente por las víctimas; lo que confirma nuestro planteamiento en torno a que el Estado desconoce o no acepta que los representantes de las víctimas formulen de forma directa otras pretensiones diferentes a las expuestas por la Comisión.

Sobre este tema la Corte puntualmente aclaró en estas sentencias que si bien las víctimas no pueden alegar hechos nuevos a los planteados en la demanda por parte de la Comisión, salvo que estos hayan sido sobrevivientes a la misma o que la narración tienda a aclarar o explicar los que han sido expuestos por la Comisión; no sucede igual con la proposición de los derechos vulnerados, pues en relación con los mismos las víctimas o sus representantes pueden agregar otros, siempre y cuando los mismos se desprendan de los hechos expuestos en la demanda, en razón de que finalmente son ellos los titulares de los mismos. A lo que se suma el hecho de que la Corte puede estudiar la violación de derechos no contemplados en la demanda, en la contestación o en el escrito de argumentos y solicitudes de las víctimas en desarrollo del principio de iura novit curia. ${ }^{20}$

19 En esta ocasión el Estado precisó que:... con fundamento en las decisiones proferidas por las autoridades jurisdiccionales y disciplinarias internas y por los hechos señalados en el literal B del Capítulo VI "Los hechos de julio de 1997" de la demanda presentada por la Comisión Interamericana de Derechos Humanos... manifiesta pública y expresamente lo siguiente... Corte Interamericana de Derechos Humanos, op . cit., nota 1.

20 Sobre el principio de iuria novit curia la Corte señaló que este se emplea: en el sentido de que el juzgador posee la facultad e inclusive el deber de aplicar las disposiciones jurídicas pertinentes en una causa, aún cuando las partes no las invoquen expresamente", en el entendido de que se le dará siempre a las partes la posibilidad de presentar 
En consecuencia, a pesar de tres intentos con similares propósitos por parte del Estado, esto es, tendientes a desconocer el papel de las víctimas en el proceso ante el Sistema Interamericano de Protección de los Derechos Humanos, tenemos que la Corte ha sido enfática en reivindicar la posición que ocupan las víctimas durante este proceso contencioso.

\section{Insistencia en formular excepciones previas a pesar de haber efectuado un reconocimiento parcial}

Otro aspecto en el que vale la pena detenerse y resulta común en los tres casos que hemos escogido es que el Estado acompaña su reconocimiento parcial de responsabilidad con la formulación de la excepción previa referente a la falta de agotamiento de recursos internos.

Lo anterior significa que, aun cuando el Estado acepta ante la Corte que concurrió en la vulneración de ciertos derechos humanos, arguye que dicho ente jurisdiccional no es competente para conocer del caso cuando las víctimas aún tienen recursos internos a los que acudir o éstos se encuentran pendiente de resolución.

Por tanto, sostiene el Estado que al tener el Sistema Interamericano de Protección de los Derechos Humanos un carácter subsidiario, la Corte debe permitir que el ente estatal, como primer llamado a garantizar los derechos de las personas, finalice todos los procesos judiciales y, por esta razón, debe privarse del derecho de acudir a esa jurisdicción internacional a quienes no hayan intentado agotar esos recursos, o frente a quienes aún no exista una respuesta definitiva.

Al respecto, la Corte considera que cuando un Estado efectúa un reconocimiento de responsabilidad, aun cuando éste sea parcial, la consecuencia es que implícitamente el Estado acepta la competencia de este ente jurisdiccional y, por lo mismo, el planteamiento que había sido formulado como una excepción previa debe ser descartado o al menos pasaría, de ser el caso, a ser un tema de fondo que sólo se resolvería una vez que se profiera la sentencia. ${ }^{21}$

los argumentos y pruebas que estimen pertinentes para apoyar su posición frente a todas las disposiciones jurídicas que se examinan. Corte Interamericana de Derechos Humanos, op. cit., nota 1 .

21 Así, por ejemplo, en la consideración núm. 30 de la sentencia sobre excepciones preliminares y reconocimiento de responsabilidad proferida por la Corte el día 7 de marzo de 2005 en el caso de la masacre de Mapiripán, el ente jurisdiccional señaló: Por otro 
La Corte ha mantenido esta postura en los tres pronunciamientos objeto de estudio, no obstante, estimamos que no resulta incompatible el que un Estado admita su responsabilidad parcial en cuanto a la vulneración de ciertos derechos humanos y, que a la vez, formule excepciones tendientes a demostrar que el juzgador carece de competencia.

Esta apreciación se sustenta en el hecho de que consideramos que una condición necesaria para que la Corte asuma competencia es que esté en litigio la posible vulneración de derechos humanos incluidos en los instrumentos de protección de los derechos humanos que integran este sistema regional, ${ }^{22}$ pero ésta no es una condición suficiente pues para consolidar su competencia se hace indispensable que el Estado no haya formulado excepciones previas o que las mismas no estén llamadas a prosperar.

En este punto se hace necesario recordar el artículo 46.1 de la Convención Americana, el cual establece que, conforme a los principios del derecho internacional generalmente reconocidos, se requiere que se hayan interpuesto y agotado los recursos de la jurisdicción interna, lo que significa que, ésta es una condición también necesaria - aunque tampo-

lado, al haber efectuado un reconocimiento de responsabilidad en el presente caso, el Estado ha aceptado implícitamente la plena competencia de la Corte para conocer del presente caso, por lo cual la segunda excepción opuesta por el Estado [falta de agotamiento de los recursos internos] ha perdido el carácter de cuestión preliminar. Además, el contenido de dicha excepción se encuentra íntimamente relacionado con el fondo del presente asunto, en particular en lo referente a la supuesta violación de los artículos 8o. y 25 de la Convención. Por lo tanto, dicha excepción preliminar debe ser desestimada y la Corte debe continuar con el conocimiento del fondo y las eventuales reparaciones y costas en el presente caso". Caso de la masacre de Mapiripán vs. Colombia, sentencia del 7 de marzo de 2005, Excepciones preliminares, de la Corte Interamericana de Derechos Humanos en http://www.corteidh.or.cr. En términos similares en el caso de las masacres de Ituango la Corte indicó: Al haber efectuado un reconocimiento de responsabilidad en el presente caso, el Estado ha aceptado implícitamente la plena competencia de la Corte para conocer del mismo, por lo cual Colombia ha renunciado tácitamente a la excepción preliminar interpuesta. Además, el contenido de dicha excepción se encuentra íntimamente relacionado con el fondo del presente asunto... Corte Interamericana de Derechos Humanos, op. cit, nota 2. Lo que también se hace extensivo al caso de la masacre de la Rochela. Corte Interamericana de Derechos Humanos, op. cit., nota 3.

22 Nos referimos a los diversos protocolos y convenciones que integran el Sistema Interamericano de Protección de los Derechos Humanos. Cfr. García Ramírez, Sergio, La jurisdicción interamericana de derechos humanos, México, Comisión de Derechos Humanos del Distrito Federal, 2006, Colección Estudios, p. 83. 
co suficiente por cierto - para que un órgano jurisdiccional internacional asuma competencia.

De ahí que, el hecho de que se haya admitido la vulneración de ciertos derechos fundamentales no conlleva, per se, a sostener que la Corte goza de la competencia para decidir el fondo del asunto, porque, eventualmente, tal como lo hemos señalado, puede carecer de competencia en virtud de otra circunstancia como la planteada en los casos en cuestión, esto es, la falta de agotamiento de los recursos internos.

Ahora bien, otra cosa es que en virtud de los numerales 3o. y 6o. del artículo 37 del Reglamento de la Corte Interamericana la proposición de estas excepciones no suspenda el procedimiento y que, incluso, esta cuestión pueda resolverse en conjunto con la sentencia de fondo, pero no por ello las excepciones previas pierden su carácter de preliminares, es decir, su propósito de demostrar que el juzgador no es competente para resolver el asunto.

Por lo que no consideramos que con el reconocimiento parcial de responsabilidad el Estado colombiano haya aceptado implícitamente la competencia de la Corte, más aún si de forma expresa formuló una excepción de contenido preliminar. Diferente hubiere sido la circunstancia si el Estado además de efectuar la aceptación de vulneración de algunos derechos humanos no hubiese formulado ninguna excepción preliminar, allí no cabría duda sobre el reconocimiento incondicional de la competencia de la Corte por parte del Estado.

Acorde con las anteriores apreciaciones podríamos cuestionarnos ¿qué sucede si la excepción preliminar prospera?, es decir, si el Estado logra demostrar que efectivamente no se han agotado los recursos internos. Bajo esta hipótesis, en nuestro criterio, si bien la Corte carecería de competencia para pronunciarse sobre el fondo del asunto, las manifestaciones realizadas por el Estado deberían tener una repercusión en el ámbito interno, en la medida en que fueron manifestaciones espontáneas de aceptación de responsabilidad hechas por el representante del Estado, por lo que estas aseveraciones lo vincularían y, por tanto, la posición de las víctimas se vería aliviada, pues, de no haberse realizado en el ámbito local, estas manifestaciones constituirían un hecho nuevo a considerar por parte del juzgador interno en la resolución del caso.

Por lo expuesto con antelación, somos partícipes de que aun cuando se haya efectuado un reconocimiento parcial o total de responsabilidad por parte de un Estado en el Sistema Interamericano, las excepciones 
preliminares formuladas deben absolverse como un paso previo al estudio del fondo del asunto para no emprender un esfuerzo que posiblemente esté llamado al fracaso, o, de ser el caso, dada la estrecha relación entre la excepción propuesta y el fondo del asunto, las excepciones preliminares deben resolverse en la sentencia de fondo en la que se determine desde un comienzo si la Corte es o no competente para evitar cualquier tipo de prejuzgamiento.

\section{EFECTOS JURÍDICOS QUE LA CORTE INTERAMERICANA OTORGA \\ AL RECONOCIMIENTO PARCIAL DE RESPONSABILIDAD DEL ESTADO COLOMBIANO}

\section{1. ¿Existen incentivos que promuevan el reconocimiento de responsabilidad por parte de un Estado?}

Un primer aspecto que quisiéramos resaltar es que por lo general las actuaciones procesales de las partes dentro un litigio suelen estar ampliamente reguladas y, por ello, en el derecho interno de cada país, existen códigos de procedimiento que establecen plazos y momentos precisos en los cuales pueden hacerse cierto tipo de proposiciones por parte de los sujetos procesales, es el caso, por ejemplo, de las excepciones previas, que sólo pueden plantearse de manera conjunta con la contestación de la demanda, y de no hacerse así, el juzgador entenderá que no hubo elementos para su formulación o que existió una renuncia tácita a este mecanismo de defensa.

Para el caso particular las normas que recogen la regulación procesal del Sistema Interamericano de Protección de los Derechos Humanos son: la Convención Americana, el Reglamento de la Comisión y el Reglamento de la Corte y, en ninguna de ellas se establece un plazo perentorio para que el Estado pueda realizar un reconocimiento de su responsabilidad sea total o parcial, lo que nos permite inferir, ante el silencio de estas disposiciones, que, en principio, el plazo para efectuar este reconocimiento sólo vence una vez que se haya dictado sentencia de fondo dado el carácter definitivo de la misma.

Así, tenemos que un Estado demandado en el Sistema Interamericano tiene la posibilidad de comunicar a la Corte su allanamiento, expresión que resaltamos porque es la que se emplea en el artículo 53.2 del Reglamento del ente jurisdiccional, sea este total o parcial sobre las pre- 
tensiones o los hechos formulados por la Comisión y/o por las víctimas hasta antes de que se dicte sentencia de fondo por parte de la Corte. ${ }^{23}$

Ante esta circunstancia nos preguntamos ¿qué diferencia habría para un Estado si éste reconoce su responsabilidad a instancia de la Comisión, o en el momento de dar contestación de la demanda ante la Corte o quizá después de concluida la etapa probatoria?

Si comparamos la situación de allanamiento de un Estado con la confesión de un imputado en un proceso penal, encontramos que para el segundo resulta de gran relevancia el momento procesal en el cual realiza su confesión en la medida en que, entre más pronto sea el reconocimiento, mayores serán los beneficios. ${ }^{24}$

Sin embargo, acorde con los casos objeto de estudio, el Sistema Interamericano de Protección de los Derechos Humanos no reporta mayores beneficios para un Estado que realiza un allanamiento en uno u otro momento procesal dentro del trámite ante la jurisdicción interamericana; incluso, vemos que un reconocimiento anticipado podría perjudicar la defensa de un Estado ante la Corte dado que, como lo ha señalado este ente jurisdiccional, una vez admitida la responsabilidad no podrá el Estado válidamente cambiar su parecer salvo circunstancias excepcionales.

A guisa de ejemplo, tenemos que en el caso Acevedo Jaramillo y otros vs. Perú, el Estado peruano reconoció su responsabilidad sobre los hechos a instancias de la Comisión, pero, una vez llegó el proceso a la Corte Interamericana, pretendía rechazar todos los hechos que se le im-

23 Incluso observamos que algunos Estados han realizado este reconocimiento a instancias de la Comisión. Cfr. Caso Montero Aranguren y otros (Retén de catia) vs. Venezuela, sentencia del 5 de julio de 2006, Fondo reparaciones y costas, de la Corte Interamericana de Derechos Humanos, en http://www.corteidh.or.cr.

24 En el caso colombiano, por ejemplo, acorde con el artículo 40 de la Ley 600 de 2000, que contenía el Código de Procedimiento Penal antes de ser derogado por la Ley 906 de 2004 que instituye el sistema oral para estas causas, se establecía que: A partir de la diligencia de indagatoria y hasta antes de que quede ejecutoriada la resolución de cierre de la investigación, el procesado podrá solicitar, por una sola vez, que se dicte sentencia anticipada... El juez dosificará la pena que corresponda y sobre el monto que determine hará una disminución de una tercera (1/3) parte de ella por razón de haber aceptado el procesado su responsabilidad. También se podrá dictar sentencia anticipada, cuando proferida la resolución de acusación y hasta antes de que quede ejecutoriada la providencia que fija fecha para la celebración de la audiencia pública el procesado aceptare la responsabilidad penal respecto de todos los cargos allí formulados. En este caso la rebaja será de una octava (1/8) parte de la pena. 
putaban sobre el mismo asunto alegando un supuesto hecho nuevo. En esta ocasión la Corte, después de pronunciarse desestimando el hecho presentado por el Estado, señaló que, conforme al principio de estoppel, un Estado no puede asumir una posición contradictoria que cambie la base sobre la cual se guió la contraparte. ${ }^{25}$

Lo expuesto, sin duda, merece una reflexión adicional pues consideramos que, si bien es cierto, el Estado tiene, por una parte, la carga de colaborar con la justicia, esto es, tener la disposición de facilitar la práctica y recaudo de todo medio probatorio, de allegar las pruebas que tenga en su poder, la carga de actuar de buena fe, es decir, no obstruir el trámite $\mathrm{y}$, por qué no, reconocer los hechos que le constan, entre otras; por otra parte resultaría más llamativo para los Estados encontrar un incentivo para un reconocimiento temprano de su responsabilidad, pues no cabe duda que resultaría más útil y ofrecería un menor desgaste para el Sistema Regional de Protección de los Derechos Humanos que los Estados no asumieran una defensa a ultranza de su posición conociendo de antemano la negligencia con que han actuado sus agentes. O lo contrario, podría la Corte asumir una postura más rígida cuando fuera evidente que el Estado pudo reconocer su responsabilidad pero no lo hizo.

En todo caso consideramos que la consecuencia de efectuar un reconocimiento de responsabilidad por parte de un Estado en uno u otro momento procesal debería tener una repercución material, es decir, que se hiciera evidente en el contenido de la sentencia de fondo, más aún, insistimos, si se desprende que el Estado conocía de antemano la concurrencia de su responsabilidad en los hechos sometidos a examen ante la Corte y no efectuó ninguna manifestación.

Con esta propuesta no buscamos que la vulneración a los derechos humanos se convierta en algo que los Estados puedan negociar ni que se abandone el principio de reparación integral en favor de las víctimas; nuestra propuesta se centra en ahondar en la posibilidad de ahorrar recursos y tiempo dentro de los procesos que se surten en el Sistema Interamericano con la finalidad de que el proceso de impartir justicia se torne más expedito.

$25 C f r$. el caso Acevedo Jaramillo y otros vs. Perú, sentencia del 7 de febrero de 2006, Excepciones Preliminares, fondo, reparaciones y costas, de la Corte Interamericana de Derechos Humanos en http://www.corteidh.or.cr. 
Los anteriores comentarios se hacen palpables en los casos objeto de estudio en los cuales encontramos una pobre remisión en los puntos resolutivos de la sentencia al reconocimiento parcial de responsabilidad del Estado que se resumen en la siguiente frase: "Admitir el reconocimiento de responsabilidad efectuado por el Estado". Enseguida, se hacen las condenas respectivas al Estado, pero en ninguna de ellas se alude al reconocimiento del ente estatal o se resalta el mismo o se le trata como una condena que ya ha sido cumplida por parte del Estado, en fin, diversas opciones que podrían concretar lo favorable que resulta para un Estado haber realizado un reconocimiento de responsabilidad con antelación o lo desfavorable que podría llegar a ser el hecho de no haber efectuado o realizado de forma tardía dicha aceptación.

En este punto podría afirmarse que las consideraciones de la Corte respecto al reconocimiento parcial de responsabilidad del Estado fueron expuestas en la parte motiva de la sentencia, donde el ente jurisdiccional resalta la complacencia con que la Comisión y los representantes de las víctimas recibieron el reconocimiento efectuado. Pero al lado de estas breves referencias sólo se califica este reconocimiento como un inicio para el cumplimiento de las obligaciones internacionales de un Estado, en el cual se destacan las expresiones empleadas por éste, alusivas a las víctimas donde expresa y públicamente les pide perdón.

Desde esta perspectiva observamos que tanto la Corte, la Comisión y las víctimas reconocen la actitud del Estado como un acto positivo, pero, ciertamente, la Corte no le da un alcance material al mismo, por lo que consideramos que debería revisarse esa postura y procurar dar algún efecto concreto al citado reconocimiento para, como ya lo mencionamos, motivar a otros Estados a que también lo realicen cuando de los sucesos debatidos así desprenda.

\section{Alcance del reconocimiento y extensión de la controversia}

Un segundo aspecto en el desarrollo del proceso sobre el cual llamamos la atención es que al presentarse un reconocimiento parcial de responsabilidad en los casos seleccionados, la Corte, antes de continuar con el conocimiento del fondo del asunto, aborda el tema como una cuestión previa en la cual delimita: i) los alcances del reconocimiento efectuado, y ii) la extensión de la controversia subsistente. 
En el primer acápite, la Corte demarca cuáles fueron los reconocimientos del Estado en relación con las pretensiones formuladas por la Comisión y las víctimas, así como con las reparaciones y costas presentadas por las mismas.

Para ejemplificar lo antedicho encontramos el caso Vargas Areco vs. Paraguay, ocasión en la cual el Estado efectuó un reconocimiento por hechos ocurridos con anterioridad a la entrada en vigencia de la competencia de la Corte, motivo por el cual el ente jurisdiccional delimitó el alcance del mismo y, aunque resaltó su importancia, determinó que su competencia sólo se extendía frente a los hechos ocurridos con posterioridad a la entrada en vigor de su jurisdicción, por lo que rechazó algunos apartes del reconocimiento efectuado por el Estado. ${ }^{26}$

Desde esta perspectiva se hace un cotejo entre cada una de las pretensiones y las manifestaciones realizadas por el Estado con la finalidad de establecer el grado de coincidencia.

Es tan detallado el estudio de la Corte que la comparación no sólo es respecto de los hechos y pretensiones, sino también sobre la delimitación temporal del reconocimiento. Por ejemplo en el caso del Penal Miguel Castro Castro vs. Perú, el Estado realizó un reconocimiento parcial que involucró tanto aspectos de la demanda de la Comisión como del escrito de las víctimas, pero expresamente señaló una limitación temporal del mismo, de la cual la Corte se ocupó en este acápite. ${ }^{27}$

Seguidamente y con base en el estudio realizado con antelación, la Corte establece qué pretensiones no fueron abarcadas en el reconocimiento de responsabilidad del Estado y sobre éstas, en los tres casos objeto de análisis, decide continuar su estudio de fondo. Aquí la Corte es muy cuidadosa en señalar los hechos y derechos que se dicen vulnerados respecto de los cuales se guiará su examen, en este punto es esencial resaltar que no podemos olvidar que la Corte ha interpretado el silencio del Estado como una aceptación tácita de los hechos y pretensiones, más cuando ha existido un reconocimiento de responsabilidad a instancia de

26 Caso Vargas Areco vs. Paraguay, Fondo, reparaciones y costas, sentencia del 26 de septiembre de 2006, de Corte Interamericana de Derechos Humanos en http://www. corteidh.or.cr.

27 Caso del Penal Miguel Castro Castro vs. Perú, sentencia del 25 de noviembre de 2006, Fondo, Reparaciones y Costas, de la Corte Interamericana de Derechos Humanos en http://www.corteidh.or.cr. 
la Comisión, por que sólo se valora en favor del Estado lo que explícitamente ha rechazado. ${ }^{28}$

En relación con el alcance que la Corte otorga al reconocimiento de responsabilidad es oportuno destacar que en el caso de Mapiripán el Estado acompañó la manifestación de reconocimiento parcial de responsabilidad junto con un requerimiento expreso en el que solicitaba a la Corte que en lo sucesivo restringiera su análisis a la delimitación de las reparaciones y costas a las que daría lugar el caso sometido a debate, en otras palabras, el Estado colombiano buscaba que una vez realizado y aceptado su reconocimiento parcial, la Corte no continuara con el estudio de fondo. ${ }^{29}$

Como señalamos en la introducción de este escrito, si bien no existe una definición o diferenciación expresa entre las figuras de reconocimiento total y parcial de responsabilidad, lo único cierto es que en el segundo evento la controversia continúa en la medida en que al ser parcial la aceptación de responsabilidad por parte del Estado quedan pretensiones formuladas expresamente por la Comisión o por los representantes de las víctimas pendientes de resolución, aspectos que la Corte está obligada a resolver si asumió la competencia del asunto, por lo cual, no podría pretenderse que un reconocimiento de tal índole, esto es parcial, finiquite el proceso.

Ahora, es necesario advertir que en algunas ocasiones el Estado no señala de forma expresa que realiza un reconocimiento parcial, pero no por ello puede pretenderse que se trate esta manifestación como un reconocimiento total, pues en todo caso, la Corte evaluará si tal como se produjo la manifestación, su contenido tiene límites, de ser así, sin duda, se está restringiendo el alcance del reconocimiento por lo cual se trataría de una declaración parcial.

28 Cfr. Caso Bueno Alves vs. Argentina, sentencia del 11 de mayo de 2007, Fondo, reparaciones y costas, de la Corte Interamericana de Derechos Humanos en http://www. corteidh.or.cr.

29 Textualmente el Estado colombiano en el caso de la masacre de Mapiripán señaló que: "4. Solicita a la... Corte se valore el reconocimiento efectuado y se le atribuya plenos efectos jurídicos, delimitando, en consecuencia, las audiencias de fondo y su posterior trámite, al estudio de las reparaciones y costas, así como a los alegatos de fondo sobre el cumplimiento del Estado de sus compromisos convencionales en relación con los artículos 8(1) y 25". Corte Interamericana de Derechos Humanos, op. cit., nota 1. 
Además, reiteramos, que cuando se trate de un reconocimiento total de responsabilidad, esto es, una manifestación que abarcara todas las pretensiones y hechos propuestos por la Comisión y las víctimas y que a su vez no tuviera ninguna clase de condicionamiento, aún en esa hipótesis la Corte tiene la potestad de decidir si continúa o no con el estudio del fondo. Por lo cual no podría convertirse en una estrategia de los Estados realizar un reconocimiento parcial para relevar a la Corte de su competencia puesto que, como lo expusimos, a la luz del artículo 55 del Reglamento de la Corte, decidir si continúa o no con el estudio de fondo de un caso es su atribución.

De allí la importancia de que la Corte decida de forma inicial abordar el alcance que dará al reconocimiento efectuado por el Estado, así como la necesidad de establecer desde un comienzo los aspectos sobre los cuales versará en lo sucesivo, la controversia para concentrar todos los esfuerzos en éstos.

Para finalizar sólo nos resta decir que los tres casos seleccionados comparten el hecho de que la Corte, una vez que concede efectos jurídicos al reconocimiento parcial de responsabilidad del Estado y delimita la extensión de la controversia subsistente, restringe el objeto de la prueba en la medida en que lo limita precisamente a los aspectos que continúan en debate, lo que evidencia la utilidad del reconocimiento parcial de responsabilidad de un Estado en el Sistema Interamericano, reflexión que nuevamente nos cuestiona acerca de la posibilidad de fomentar esta actitud entre los Estados.

\section{CONCLUSIONES}

El reconocimiento parcial de responsabilidad de un Estado no fue previsto de forma expresa en ninguno de los instrumentos que rigen el Sistema Interamericano de Protección de los Derechos Humanos. Sin embargo, esta respuesta de los Estados ha sido desarrollada en el ámbito jurisprudencial por parte de la Corte, la cual se ha encargado de dar efectos a tal manifestación de acuerdo con cada caso en concreto.

Rescatamos la actitud del Estado colombiano en el sentido de reafirmar su compromiso con la jurisdicción interamericana en la medida en que ni la Comisión ni la Corte son ignoradas por el Estado que participa de forma activa a lo largo de trámite que se surte ante estas instancias, lo 
que evidencia la importancia y reivindicación de estos organismos internacionales.

Los casos seleccionados para este escrito nos permiten sostener que el reconocimiento de responsabilidad de un Estado puede darse en cualquier etapa procesal previa a la sentencia de la Corte, en el Sistema Interamericano. No obstante, el Estado debe ser cauteloso toda vez que el reconocimiento se evalúa desde la etapa surtida ante la Comisión, lo que significa, que no podría haber una contradicción entre la postura asumida por el Estado en esa instancia y la que eventualmente adopte ante la Corte. Además, agregamos el cuidado con que deben actuar los Estados en la medida en que los puntos que no se reconocen deben ser explícitos pues cualquier silencio en relación con los hechos o pretensiones de la Comisión y/o de los representantes de las víctimas se tomará como un reconocimiento tácito.

La Corte Interamericana ha esclarecido, mediante sentencias reiteradas, la situación de las víctimas en el Sistema Interamericano de Protección de los Derechos Humanos concretamente ha señalado que no sólo pueden participar activamente durante el trámite, sino que es viable que las mismas aporten hechos que puedan corroborar o fortalecer los que fueron expuestos en la demanda de la Comisión y, además, están habilitadas para formular de manera autónoma pretensiones diferentes a las expuestas por la Comisión. Con ello surge la obligación ineludible del Estado de efectuar un pronunciamiento expreso sobre dichas manifestaciones, por lo que resulta inadmisible que aún hoy el Estado colombiano se rehúse a valorar los señalamientos efectuados por las víctimas que en últimas son las titulares de los derechos humanos que se estiman vulnerados.

Acorde con lo señalado por la Corte, cuando un Estado admite su responsabilidad sobre la vulneración de determinados derechos humanos indirectamente renuncia a la formulación de excepciones previas, conclusión que nos parece debe replantearse, pues estas peticiones necesariamente requerirán de un pronunciamiento de la Corte y postergarlo a la finalización del trámite sólo traerá como consecuencia un posible fallo inhibitorio que bien puede evitarse si se resolvieran estos asuntos con la vocación que tienen, es decir, de forma anticipada al avance del proceso.

Si el propósito del Estado fue buscar que la Corte, después de conceder plenos efectos jurídicos a su reconocimiento parcial de responsabilidad, aun cuando este se haya presentado como un allanamiento total a las pretensiones, se limite a fijar las reparaciones y costas del caso en cues- 
tión, esta estrategia no ha prosperado. Lo anterior con fundamento en que la Corte se haya habilitada expresamente por su Reglamento para determinar los efectos que dará a la manifestación realizada por el Estado, por lo mismo, válidamente puede decidir que el estudio de fondo continúe sobre algunas o la totalidad de las pretensiones formuladas por la Comisión o las víctimas. En consecuencia, el único efecto práctico que la Corte ha dado a ese reconocimiento es circunscribir de mejor manera la etapa probatoria a los aspectos que considere continúan en debate.

Hay que aprovechar cualquier ocasión para ahorrar recursos y emplearlos sólo cuando estrictamente sea necesario. Como hemos demostrado, el reconocimiento parcial de responsabilidad sintetiza el trámite contencioso, por cuanto los aspectos que reconoce el Estado son relevados de prueba circunscribiendo esta etapa procesal sólo a los aspectos que continúan en debate lo que, sin duda, genera un ahorro de recursos económicos, de personal y de tiempo. Por lo anterior, debería generarse una postura al interior de la Corte que incentive a los Estados a realizar este tipo de reconocimientos y de alguna manera reprender a los Estados que, concientes de su participación en la vulneración de derechos humanos, no efectúan tal manifestación, mas si de los hechos y de la evaluación previa que se ha realizado por parte de la Comisión así se deriva. Recordemos que actualmente la falta de reconocimiento de responsabilidad de un Estado sólo tiene un efecto de demora en el trámite y quizá una sanción moral por no haberlo efectuado, panorama que no varía mucho si el Estado tiene la iniciativa de realizar este reconocimiento. 